\title{
Parameter Calculation Error due to Application Program Problem
}

National Cancer Institute

\section{Source}

National Cancer Institute. Parameter Calculation Error due to Application Program

Problem. NCI Thesaurus. Code C63083.

Problem associated with the written program code or application software used by a device to calculate parameters other than those related to dose or power. 